dispensing drugs that every one of them has gradually gotten into the same habit of looking for cheap preparations. A man ordering 500 Blaud's pills will send out requisitions and get prices on this quantity, and nine times out of ten he takes the cheapest. He does not buy ine best that can be had because the best will cost from 20 to 100 per cent. more than he would have to pay for the same pills from irresponsible manufacturers.

DR. N. B. BAYLEx, Haverstraw, N. Y., said that he thinks the physician is as apt to buy cheap drugs as the pharmacist who dispenses the physician's prescriptions. He does not believe that the physician will buy the cheapest, that is, the poorest drugs. He will learn the reliable firms from whom to purchase, as well as the pharmacist. Dr. Bayley has seen the physician who writes prescriptions order equally as many drugs for the individual patient as ne who dispenses from his office; it is the physician and not the manner of prescribing that dictates the result. That unwise patients will give their prescriptions to their friends to have filled and used, may be some financial discredit to the physician, but on the whole that is not a large evil. As to whether a physician shall dispense or prescribe, the environment and exigencies of his practice will be the best guide. He can do either or both without criticism. The worst evil in prescribing drugs is to order mixtures and compounds of which the physician has little or no knowledge of the contents-and this irrespective of the fact whether he dispenses or writes prescriptions.

Dr. C. S. N. Hallbera, Chicago, said that he sometimes hears of irregular, quackish practices pursued by members of the regular profession. In regard to the statement, "We know the druggist buys the cheapest drugs," Dr. Hallberg asked how the physician making the statement knows that, and if he is familiar with the tests of the Pharmacopeia. Physicians know nothing about that. It is the prerogative of the pharmacist to identify and to pass on the purity, quality and strength of medicines. The physician is neither by training, experience nor environment fitted to it. Why, he asked, bring in these irregular practices of substitution and of prescriptions being refilled without the physician's order? What else can one expect when in Boston the "largest retail drug establishment in America" prides itself on the fact that for nearly one hundred years it has never kept a prescription on its file, but hands it back to the patient. Physicians are to blame. What physician in Boston has any right to send a prescription to such an establishment which does not understand the first principles of pharmacy or medicine? The pharmacist is the only one who is competent to compound, prepare and, except in case of emergency, to dispense medicine. The fact that many violate this and counter prescribe has nothing to do with it. Who are the directors of the "World's Dispensary?" Who is the proprietor of the "Salveda" remedies? They are the doctors. There are physicians who are just as bad or worse than the pharmacists. It would be no more proper to accuse the pharmaceutical profession of irregular practices because they do occasionally counter prescribe, or because they do occasionally substitute than it would be to accuse the medical profession because there are advertising quacks and all kinds of fellows in their ranks. This question is "up to" the doctors. Physicians should demand that a prescription shall not go out of the hands of the pharmacist, and should give instructions to the pharmacist that the prescription is not to be repeated except on special order. The patient has no right whatever to the prescription. Dr. Hallberg admits that there are a few things which the physician may properly dispense. If physicians years ago had written for "Liquor ferri mangrani peptonatus," people would not be haunting bargain stores asking for "pepto-mangan," and they would not be able to get it. There is a reasonable medium in this. There is no use in the pot calling the kettle black. Let us try and get together. Wherever a physician is located let him find a competent, honest, skilful pharmacist. The members of the American Pharmaceutical Association are found in almost every state. They are not sublime, but there is something that holds them together, and wherever one finds a member of the American Pharmaceutical Association, one can say, "My friend, I don't want that prescription to be repeated," and it will not be repeated.

Dr. M. H. Fussels, Philadelphia, declared that the vast majority dispense pellets, pills and compressed tablets. Many of these compressed tablets and pills are compound concoctions and there is no more reason to say that because a foolish physician will prescribe many things in one prescription that it justifies dispensing tablets containing numerous ingredients. Dr. Fussell said that men in his neighborhood, many of them reputable gentlemen, most of them graduates from the University of Pennsylvania or from the Jefferson Medical College, when they started to practice medicine, started to practice decent medicine and very soon fell away because, as a candid physician told Dr. Fussell just before he started for the session, "I tried for six months to do as you asked me to do, and regularly every six months $I$ went to my people for the money for my rent. I put drugs in my office and $I$ haven't had to go once."

\section{A METHOD OF RECORDING CHANGES IN BODY WEIGHT WHICH OCCUR WITHIN SHORT INTERVALS OF TIME.*}

WARREN P. LOMBARD, M.D. ANN ARBOR, MICH.

Exact determinations of the rate at which metabolism is occurring within the body are of great practical as well as scientific interest. It is doubtful whether any method can be devised which will give more accurate results than those obtained from a subject living in a respiratory chamber, but this method in its most complete form requires an expensive plant, can not be used in the case of the sick and fails to give changes which occur within short intervals of time. In the hope of developing a method which, even though less exact, might be sufficiently accurate to meet practical requirements, and give information concerning changes in metabolism which occur from minute to minute, the work recorded in this paper was undertaken.

Higley, working with Bowen in the physiological laboratory of the University of Michigan, found that the movements of a delicate balance could be recorded on the blackened drum of a kymograph, without impairing the sensitiveness of the balance to any considerable extent. It was therefore thought that if a balance could be constructed capable of wejghing from 70 to 80 kilos, with nicety, and if the scale pans had the form of a mattress, a man might lie at ease on one of the pans, and the rate of loss of weight per minute or any longer interval of time could be readily recorded, and the amount of weight at any given moment be determined.

\section{DESCRIP'TION OF BALANCE.}

Such a balance was constructed in the shops of the university, but it was found to be too sensitive to be used alone, for a man may lose more than a gram a minute, which is more than sufficient to turn the balance through the desirable working distance. It was therefore found to be necessary to control the movement of the balance by means of a spiral spring attached to one of its arms, i. e., to weigh by means of a combination long-arm and spring balance.

As used at present, the balance supports the weight and the spring does the weighing. The spring is fast-

- Read In the Section on Pathology and Physlology of the American Medical Association, at the Fifty-seventh Annual Session, June, 1906. gan. 
ened from above to the arm of the balance which supports the man; this side is over-weighted by 3 or 4 gm. and as the man loses weight, the spring contracts, drawing the arm of the balance upward. The spring is so arranged, that it can be attached to any desired part of the arm of the balance and so given any suitable leverage. The movement of the balance is recorded on a kymograph drum by means of a long lever, which magnifies the movement about ten times, and which is connected by means of a steel rod with the arm of the balance carrying the man. To avoid friction, the connecting joints are knife-edges, resting in grooves. The writing lever can be regarded as a delicate balance, a writing point suspended from one end to the lever, and a counterbalancing weight at the other end, having the places of the usual scale pans. The writing pointer is a light stiff strip of bamboo, $14 \mathrm{~cm}$. long and $4 \mathrm{~mm}$. wide, tipped with a paper writing point. The writing pointer is fastened a little to the inside of the center of the axis from which it is suspended, and so tends to swing slightly out of the vertical plane. This tendency is sufficient to keep the point always resting lightly against the drum.

With this apparatus it has been possible to obtain graphic records of the total loss of weight of a man or a $\operatorname{dog}$, for example, during 2 minute intervals, at a number of periods within a few minutes of each other. The loss during longer intervals could be readily obtained by increasing the leverage of the spring, or using a stronger spring.

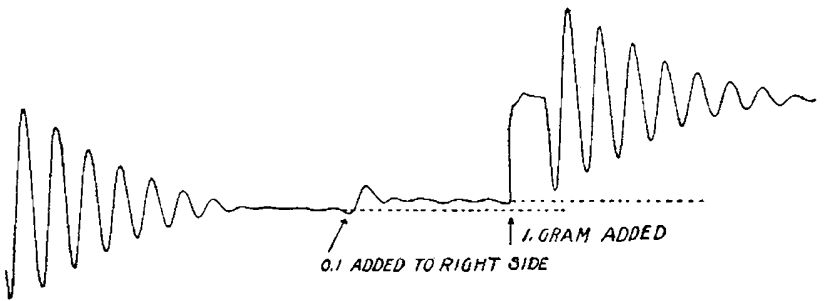

Fig. 1.-Test of balance when connected with the phosphor-bronze spring and loaded with 80 kilos on a side. The curve shows that it oscillates freely, and that 0.1 gram caused an evident deflection.

The balance itself is made of stiff steel tubing, welded into strong central and lateral brass castings, and has the form of the walking beam of an engine. The central knife-edge is about six inches long, and is made from a triangular bar of very hard cold drawn steel. It is supported at the ends in groves cut in two plates of well hardened steel. These plates rest on a horizontal steel bar, which is fastened at each end to a strong iron casting. These castings are secured by heavy lag screws to two $6 \times 6$ wooden. joints which extend from the floor to the ceiling, where they are securely fastened. The plates containing the grooves for the knife-edge are not fixed on the supporting iron bar, but are free to make a certain amount of movement. Two bolts pass through holes in the iron bar and screw into the bottoms of the plates, but as the holes in the bar are a little large for the bolts, the plates can rotate and shift their position slightly in the horizontal plane. Moreover the bottoms of the plates are slightly convex in the direction of the groove and hence can rock a little on the supporting bar. The fact that the plates are free to move slightly in all but the vertical direction, enables the knife-edge to adjust the grooves to itself when it is placed in them. This arrangement reduces the friction between the central knife-edge and the grooves to a minimum, and gives the balance its great sensitiveness.
When at rest and weighted with 80 kilos on a side, the balance will turn to $.02 \mathrm{gm}$. When in motion, it has a period of swing of 70 seconds for a double oscillation, and is still more sensitive to changes in weight. One decigram will cause the record on the drum to deviate $10 \mathrm{~mm}$. As one can read two-tenths of a millimeter readily, a change in position of the balance corresponding to $.002 \mathrm{gm}$. can be observed.

As has been said, the sensitiveness of the balance is so great that it is necessary to control its movements by connecting a spiral spring to one of the arms. The spring in use has an initial tension of $5.3 \mathrm{gm}$. and the balance thus harnessed, has a period of swing of about 50 seconds for a double oscillation, and one decigram deflects the lever about $2.7 \mathrm{~mm}$. The errors due to calibration and reading the curves are probably now not more than 3 or 4 per cent., and with further refinement of the method, which is still in its infancy, will probably not to be more than 2 per cent. Figure 2 shows the curve of the loss of weights of alcohol, from an alcohol lamp burning on one of the scale pans of the balance.

\section{EXPERIMENTS.}

Not very many experiments have thus far been made, as the apparatus is undergoing modifications as to its finer details. The tables will serve to give an idea of

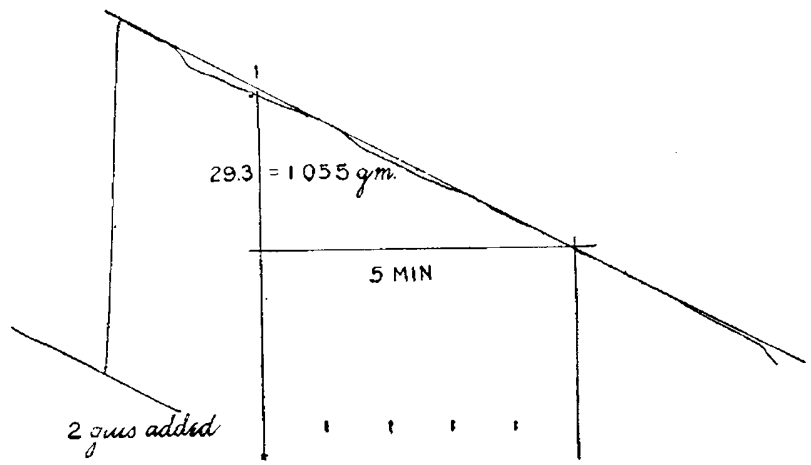

Fig. 2.-Curve recorced by balance when an alcohol lamp was burning on the right pan, the balance being loaded at the time with 80 kilograms on each side. When 2 grams was added to the side on which the lamp was, and the pan went down, the recording lever rose; as the lamp burned, the lever fell.

the character of the results which have been obtained and the possible uses of the instrument.

An experiment made on two men and one dog at about the same part of the same day, March 17, 1906, the room temperature being $18 \mathrm{C}$., gave the results in Table 1.

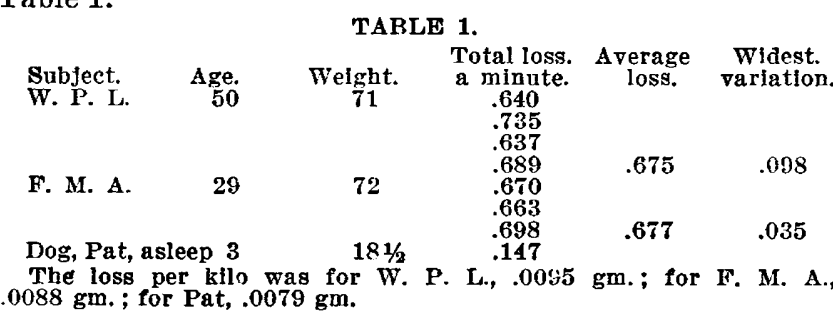

Table 2 gives the results of experiments made on a man on three different days.

Apropos of the accuracy of the records of the balance, it is to be noticed that this man weighed 72 kilos, a little over 72,000 milligrams, and that the five determinations of the loss of weight on May 19 ranged from 505 to 529 milligrams, a difference of about 24 milligrams.

An illustration of the rapidity with which the balance responds to changes in the loss of weight is to be found 
TABLE 2.

F. M. A., aged 29, welght 72 kilos.

Date. Temperature. Total loss of weight a minute. Skin loss. Lung loss. May $17 \quad 271 / \mathrm{C}$

\begin{tabular}{|c|c|c|c|c|c|c|}
\hline & & & $\left.\begin{array}{l}1.260 \\
1.165 \\
1.228\end{array}\right\}$ & $\begin{array}{l}\text { A } \\
\text { (foot hurts) }\end{array}$ & & \\
\hline & & & $\left.\begin{array}{l}1.210 \\
1.010 \\
1.042 \\
1.123\end{array}\right\}$ & B & $\begin{array}{l}.456 \\
.439\end{array}$ & \\
\hline May 19 & $22 \mathrm{C}$ & Average & $\left.\begin{array}{l}1.171 \\
.526 \\
.529 \\
.519 \\
.505 \\
.512\end{array}\right\}$ & $\begin{array}{l}\mathrm{A} \\
\mathrm{B}\end{array}$ & .447 & .724 \\
\hline & & Average & .518 & & & \\
\hline May 24 & $24 \frac{1}{1 / 2} \mathrm{C}$ & A \{ & $\left\{\begin{array}{l}.828 \\
.807 \\
.781\end{array}\right.$ & & $\begin{array}{l}.356 \\
.371\end{array}$ & \\
\hline & & &. .673 & & .371 & \\
\hline & & $\mathrm{B}\{$ & $\begin{array}{l}.637 \\
.778 \\
.677 \\
.457 \\
.617\end{array}$ & $\begin{array}{l}\text { (asleep) } \\
\text { (awake) }\end{array}$ & $\begin{array}{l}.209 \\
.327\end{array}$ & \\
\hline & & Average & 706 & & 327 & .379 \\
\hline
\end{tabular}

in the curves obtained in experiments in which the breath was held. Often, in five or ten seconds after the man stopped breathing the slope of the curve changed, flattening as the loss from the lungs stopped; when the breathing was begun again, the respirations were very deep for a time, to remove the carbon dioxid which had a state of activity to one of rest, is shown generally in the experiments. The loss of weight is always greater in the observations made soon after the subject takes his place on the balance than in those made after he has been lying there some time.

Still another illustration of the capacity of the balance to reveal slight changes in metabolism was observed in the record of May 1\%. The results of four successive observations were: $1.327,1.260,1.165,1.228$. The rate of loss of weight was lessening as the subject quieted down, until the last observation, when it was higher. This last observation came at the end of the drum, when the subject asked if he could change his position as his foot was becoming uncomfortable.

When the breath is held, the loss of weight depends on the rate of excretion from the skin alone. This, of course, should vary with the temperature and the amount of moisture in the air. The effect of external temperature on the rate of loss of weight from the skin was shown in the above experiments on F. M. A.

Temperature 22 C., May 19, loss per minute, 0.161

Temperature $24 \mathrm{C}$, May 24, loss per minute, .356, .371, .371 $209, .327$

Temperature, $27 \mathrm{C}$, May 17 , loss per minute, .0456, .439.

None of the figures which have been given is of any especial value, except as suggestions of character of the results which may be expected from the method.

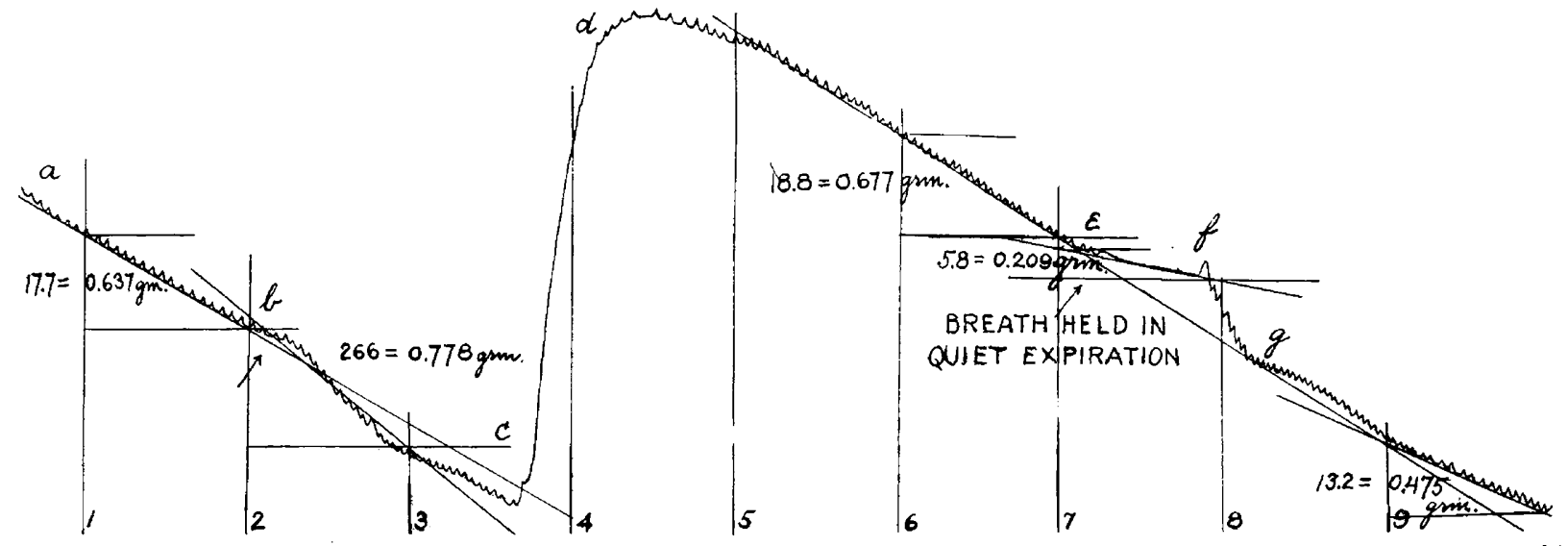

Fig. 3.-Curve of loss of welght of F. M. A. (aged 29, weight 72 kilos.), $5: 30$ p. m., May 24, 1906. lioom temperature, 24.5 c. : hygrometer, 55 degrees, The small oscillations were caused by the respirations. Time is marked in minutes at the bottom of the curve. a-b, subject asieep; b-c, waking curve; at c, 4 grams added; d-e, waking curve; at e, breath held in quiet expiration; at $f$, a curve. a-b, subject asleep; b-c, waking curve; at c, 4 grams added; d-e, waking curve; at e, breath held in quiet expiration; at $f$, a
large inspilation when subject beglns to breathe; $f-g$, curve shows rapid loss of welght following the holding of the breath. At b, he was partiy asleep, eyes closed, lids twitching. He was told to open his eyes and did so. He was not startled and was not seen to make any other morement

been held back, and the curve fell more rapidly than before the holding of the breath; soon the curve flattened again, showing the rate of loss of weight to be decreasing. For a time, the rate of loss was less than before the breath had been held, because the improved ventilation of the lung following the holding of the breath lessened the output from the lung for a time. Finally the curve resumed its original slope.

Another illustration of the sensitiveness of the balance to small changes in the rate of loss of weight is to be found in the difference in the rate of loss of weight during sleeping and waking (see Fig. 3). During the experiment on F. M. A., May 24, the subject appeared asleep. The eyes were closed and the lids twitched. $\mathrm{He}$ was spoken to quietly and told to open his eyes. He was not startled and made no movement except to slightly change rhythm of respiration at the moment he was spoken to. The curve of loss of weight was seen to change its course as the eyes opened, beginning to fall more rapidily, showing probably an increased metabolism. The fact that the metabolism lessens as one passes from
Higley found that two tubes, one bringing air and the other taking it away, can be connected with a balance without appreciably altering its sensitiveness. It is possible, therefore, for a man, while lying on a pan of the balance, to receive outside air through one tube and to give off air that he has breathed by another tube, at the same time he is being weighed.

The loss of weight from the lungs is the algebraic sum of the carbondioxid lost plus the water lost, minus the oxygen absorbed. If the subject should breath through a train of tubes, the first containing sulphuric acid to take up the water of the breath, and a second containing soda lime, to absorb the carbon dioxid given off, the amount of the loss of water and carbon dioxid from the lungs could be determined by weighing the tubes before and after the experiment. Further, if this train of tubes was on the same side of the balance as the subject, so that what he gave off from the lungs was held beside him on the balance, any recorded change in weight would be due to the loss of water from the skin and gain of oxygen by the lungs. If the loss by the skin was known, 
the gain of oxygen could be calculated. A correction would have to be made for the water and carbon dioxid in the air breathed, or these would have to be removed before the air reached the subject.

'Lheoretically, it is possible by the gravimetric method to ascertain the total loss of weight by the body per minute, and to differentiate between the loss of weight from the lungs and skin, and this has been done in a number of cases. In addition to this, the loss of water and of carbon dioxid from the lungs, the gain of oxygen by the lungs, and, therefore, the respiratory quotient probably can be obtained. This has not been done, the development of this part of the method being as yet incomplete. How accurately the respiratory quotient can be ascertained by this method, and what difficulties may arise in the practical application of the method remain to be determined.

\section{DISCUSSION,}

Dr. D. V. N. Dearborn; Boston, enquired whether Dr. Lombard had made any studies of mental activity, as that would secm to be a proper method of getting at the mathematical status of that problem.

Dr. Lombard said he had made no studies along that line that he cared to speak of then. When the patient wakes up there is a reaction. He had evidence of that. He did not think the loss of brain activity would show itself, but if there is brain activity there is change in the muscle tone which might show.

Dr. Gramam Lusk, New York City, said that the same amount of oxygen would be given off by the same man. The differences which were noted were probably due to cases in which temperature varies according to differences in loss of moisture from the body. This depends on the temperature and the humidity of the air. At $27 \mathrm{C}$. there is comparatively small loss of heat, while at $22 \mathrm{C}$. the greater part of it would be lost through radiation.

Dr. S. J. MeLTzer, New York City, asked if the accumulation of earbon dioxid in the blood while the patient is holding his breath might not stimulate the sweat nerves and thus cause a loss of weight due to a greater production and evaporation of sweat?

Dr. Lombarid expected that the curve would go down more rapidly when the man was holding his breath, because he was then performing a muscular act. He found the other thing, however. Occasionally he found that if he holds his breath for a considerable length of time, instead of it going down slowly it will go down rapidly. If he holds only as long as he can conveniently do so, and then begins to breathe, he very rapidly regains his normal breath.

\section{THE OPSONIC INDEX IN MEDICINE.}

\section{NATHANIEL BOWDITCH POTTER, M.D. NORMAN E. DITMAN, M.D \\ ERNEST B. BRADLEY, M.D. \\ NEW YORK CITY. \\ (Continued from page 1725.)}

SPECIFICITY OF OPSONINS.

The results obtained by Wright and Douglas and by Bulloch $^{26}$ indicate the specificity of the opsonins, but to us the question seems as yet unsettled. Wright and Douglas $^{\mathbf{6}}$ assume that a high degree of specificity exists, though their experiments, in which there was a decrease in the staphylococcic-opsonic index of serum to which typhoid bacilli had been added, would suggest that different bacterial opsonins possessed part of their power in common. Bulloch ${ }^{28}$ bases his conclusions on the following experiments: Serum after being digested at 37 C. with staphylococci was freed from the bacteria by centrifugalization. when it was found that the supernatant,

26. Lancet, Dec. 2, 1905, p. 1603 clear serum had lost all opsonic power for staphylococci, but "largely retained" the opsonins for tubercle bacilli; and, conversely, serum digested at $3^{\text {ry }} \mathrm{C}$. with tubercle bacilli and cleared by centrifugalization lost its tuberculo-opsonic power, but retained that for staphylococci. Simon, using his dilution method for estimating phagocytosis, has repeated these experiments a number of times, and in every case the opsonic power for staphylococci and for colon bacilli declined in about the sameratio.

Our experiments also give opposite results from those of Bulloch. Normal pooled serum from four healthy men was used in our test. This was divided into three parts and placed in tubes. In one tube staphylococci were thoroughly mixed with the serum, in another colon bacilli were mixed with the serum, and the third tube was used unaltered as a control. These were placed in the incubator at $37.5 \mathrm{C}$. for forty-five minutes, and at the end of that time were subjected to centrifugalization at high speed for thirty to forty minutes. The serum digested with staphylococci showed an opsonic index (the control tube being taken as 1.0) against staphylococci of 0.55 , against colon, 0.12. The serum digested with colon bacilli gave an index against staphylococci of 0.26 , but against colon of 1.4 .

The high figures for the staphylococcic-opsonic index of the serum digested with staphylococci $(0.55)$ and for the colon-opsonic index of serum digested with colon bacilli (1.4) are without doubt due to the fact that the bacteria were not thrown down completely by centrifugalization; but the results are given, as they show that staphylococci take from serum not only the opsonin for staphylococci, but also that for colon, and vice versa.

\section{NON-BACTERIAL OPSONINS.}

Opsonins for other cells than bacteria have been described. Hektoen ${ }^{16}$ found opsonins for blastomycetes and probably trypanosomes. Barrat ${ }^{27}$ and Hektoen have observed the presence of hem-opsonins in the sera of normal animals. We, working with human sera, have observed it twice in the serum of colored people with tuberculous lesions.

It is now well known that there are different kinds of bacterial antitropins, e. g., antitoxins, agglutinins, precipitins, lysins, and opsonins. Antitoxins neutralize the poisonous effects of certain bacterial toxins, the best known being those of diphtheria, tetanus, and botulismus. When, however, we investigate the blood fluids of animals inoculated with vaccines and bacterial products other than those mentioned, it is found impossible to demonstrate the existence of antitoxins, or, at any rate, the quantity of antitoxin is so slight that it eludes demonstration. On studying the experimental typhoid and cholera infections, Pfeiffer showed that the protective properties of the immune sera in these diseases are due to the presence of Iysins. Experiments made in succeeding years have shown, however, that this doctrine of lysis is not of universal application. The study of immunity against microbes, like pneumococcus, staphylococcus, streptococcus, gonococcus and tubercle bacilIus, has led to the greatest diversity of opinion; some claiming antitoxic properties, others lytic, and others phagocytic properties for the different sera.

\section{INFLUENCE OF VARIOUS INFECTIONS ON OPSONINS.}

In view of these facts, it is of interest to determine what infections influence the opsonin formation in the body as well as the effect of vaccines and antitoxins on opsonins.

27. Proc. Royal Soc., 1905, vol. lxxp, p. 524. 